\title{
A Psychological Accounting of a Modern Luddite: Ted Kaczynski AKA the Unabomber
}

\author{
Anoop Gupta* \\ Faculty of Education, Department of Psychology, Canada \\ *Corresponding author: Anoop Gupta, Faculty of Education, Department of Psychology, Canada
}

Submission: 漹 July 07, 2018; Published: 海 November 13, 2018

\begin{abstract}
Ted Kaczynski's, the so-called Unabomber's, writings are being achieved at his alma mater, The University of Michigan. His well-known works have been looked at for merit as works of social philosophy or social criticism, though he is more notoriously known for sending mail bombs that killed three and injured twenty-three.

Purpose: The purpose of this study is to understand the psychological motivations of Kaczynski. More broadly, in these days after $9 / 11$ where there is vast concern about terrorism, this look into the case of Kaczynski offers a glimpse of how an abnormal psychology can be blended with social concerns to awful effect. I endeavour to construct a psychological profile based on research that has already been known about him. I shall claim he has a personality disorder, that is, an enduring pattern of thinking and behaviour that begins in adolescence, is deviant, stable, and led to distress and impairment (Diagnostic Statistical Manual of Mental Disorders-5 [1]. From a practitioner's point of view, I shall consider how educational institutions or other practitioners may better attend to clients' needs to assist them avoid personality disorders and the attendant social problems that they can bring with them.
\end{abstract}

Method: Using a case study method, I shall study the writings of Kaczynski, along with other supplemental materials and commentaries. Since I have never interviewed him, nor have I tried, I could not attempt a psychological diagnosis about his mental health, which is not my purpose. Although, according to the DSM (2000), a diagnosis must consider long-term patterns and be supplemented by other material than interviews, both of which I can claim for my purposes. By looking to his major writings, which are replete with psychological language and clues, detailing his thinking, and well documented major events in his life, laying bare his behaviour, I seek to offer an explanation along the lines of attachment theorists that is broadly theoretical. I wish to show how his behaviour and patterns of thinking are consistent with what we know about personality disorders.

Keywords: Ted kaczynski; Unabomber; Domestic terrorism; Narcissistic personality disorder; Personality disorders

\section{Narcissistic Personality Disorder (NPD)}

Personality disordered are grouped together under three clusters in the DSM-5. Cluster A deals with the paranoid and schizoid; Cluster B the anti-social, borderline, and NPD; and finally, Cluster Chouses the avoidant, dependant, and obsessive-compulsive types. Narcissistic personality disorder is "a pervasive pattern of grandiosity (in fantasy or behaviour), need for admiration, and lack of empathy beginning in early childhood and present in a variety of contexts" [2].

Some examples of the traits are thus: Reacting to criticism with feelings of rage; interpersonally exploitative, taking advantage of others; exaggerating achievements and talents, as well as having a sense of superiority (e.g., ethnocentrism or collective narcissism $[3,4]$; belief that oneself is unique and only understood by special people (e.g., "(a) she is special, and therefore (b) there are certain classes of people she shouldn't have to deal with, such as those viewed as poor or dirty" [5]); preoccupied with fantasies of unlimited power, brilliance, beauty, ideal love; feeling entitled, (e.g., "not having to wait in line"); requiring constant attention and admiration (desire for self-esteem); lacking empathy; deficient in communal orientation; struggling with intimacy and attachment; and preoccupied with feelings of envy $[1,6]$.

It has been conjectured that narcissism is part of dynamic with fragility [7-9]. In a paper, "Behind the Mask: Narcissism and Explicit Self-Esteem," [10] suggest that for the narcissist, high explicit self-esteem (which deliberate and controllable) acts as a mask concealing a fragile self in constant need of validation (i.e., low implicit self-esteem, which is automatic and uncontrollable). NPD is a coping mechanism for shame, to conceal implicit feelings of inadequacy, often projected on to others, co-existing with feelings of grandiosity [6,9]. "As a result, individuals with fragile self-esteem are defensive and highly reactive to events that threaten their positive attitudes towards themselves" [10]. They are more at prey to changing circumstances because of their inner fragility $[11,12,4]$.

For attachment theorists, early life experiences are said to have an enduring effect on personality organization, providing protective or risk factors for mental well-being. Attachment representations are formed (i.e., internal working models) activated in specific circumstances that shape experiences and guide behaviour in interpersonal situations, becoming implicit. Attachment influences: 
1. The way experiences are encoded and interpreted

2. Expectations about how the world will unfold;

3. Affective evaluation of interpersonal encounters;

4. Implications one deduces;

5. Goals, scripts, and intentions that are formed in response to interpersonal cues [13].

Secure attachment patterns are characterized by positive models of the self and other; inconsistent or constant rejection gives rise to negative interpersonal models (e.g., "I'm not worthy of consistent attention and care"), such as anxious or avoidant styles of attachment. Consequently, solitary independence is the preferred mode of existing for the narcissist. In the case of NPD, the self is viewed as superior but unacknowledged, with others failing to provide unconditional devotion. Simonsen [14] remark, "Narcissistic personalities tend to reconstruct realty to match their image, which they are unable or unwilling to give up" (p. 240). Thus, narcissists are likely to seek out people who see them as they themselves do. Not surprisingly, they often choose trophy wives, preferring high status over intimacy [15-18].

\section{Interestingly, narcissism likely relies on the well-known phenomenon of attribution bias}

Attribution theory assumes that people are motivated to interpret their environment in ways that protect and enhance a positive self-image. That is, they will attribute their success or failures to factors that help them to feel as good as possible about themselves. Consistent with these assumptions, the research on attributions for success and failure shows that attributions for success are unusually internal whereas attributions for failure are usually external [19].

Attribution bias leads the narcissist to think that if they are successful, it is because of their effort and intelligence; if they fail, it is the circumstances beyond their control. To feel good about ourselves and those we like, it would seem narcissists often view their ilk's successes as triumphs of the individual and excuse their failings as circumstantial and beyond their control (they're missing a parent, they lacked money etc.). Yet narcissists, it is reasonable to think, judge others, especially those they do not like, as having success because of external factors, not their own efforts. Thus, there is the fundamental attribution bias [18] of overestimating personal factors and underestimating situational factors in evaluating ourselves and others. Attribution theorist consider three factors related to success or failure, which can be posed as questions:

a. Is the cause internal or external? (locus of control)

b. Can things change? (stable or unstable)

c. Can I do anything aboutit? (controllable or uncontrollable)

Attribution is important. If a student, for example, believes they did poorly because "the teacher hates me" (external locus of control), the teacher will continue to give me low grades (stable variable), and nothing can be done by me to change the instructor's view (uncontrollable variable), it will likely effect motivation and behaviour: the student may stop trying because they believe it futile. As a cognitive bias, skewed attribution probably serves some function to keep upbeat about oneself (and downbeat about our enemies), but this could easily become pathological and inhibit learning. If no failures are one's fault, there is nothing to learn and nothing to change.

Nacissism could be functional and has been described as a "mixed blessing" [20]. Given the psychological dynamics of the narcissist, it is more likely they are to be psychopathic [21]. Their behavioural activation system (BAS) may override their behavioural inhibition system (BIS), when they seek validation. That is to say, the narcissist is apt to engage in risky behaviour to achieve their ends [14,20-23]. In a study, Carson 2011 considered how self-perceptions, other's perceptions, and meta-perceptions (how one thinks others see them) differ for narcissists than from the general population. Not surprisingly, narcissists saw themselves as more intelligent, extroverted, open to experience and agreeable. They report having more friends (but the perception was not reciprocated) [24], and those with PDs generally have a less robust social network. For instance, those with BPD have more broken relationships; conversely, those with no-PD have more positive relationships characterized by trust and support.

Narcissists were aware they were viewed as such by others, but perhaps did not care as they want to impress others, not be liked by them. They operate by way of dominance (status consequent to force, threats, and intimidation), not prestige (status earned by knowledge, wisdom, and earned respect) [9]. In a study of social media postings, narcissists use more "I, me" words than "we, us" terms [22]. Their language was more agency cantered (i.e., dominant, confident), than communal (i.e., friendly, generous). Narcissists have a failure of introspection or insight, and thus are reticent [5]. As Wallace puts it, "Narcissists are less likely to learn from mistakes because they blame everyone but themselves for negative outcomes".

Yet in relationships the narcissist may become more committed over time when they have spouses that elicited communal traits [25]. That is, when partners make them feel loved or cared for. Therapy involves attempts to reverse early maladaptive schemas (i.e., broad pervasive themes about the self, relations with others) that lead to dysfunction because secure attachment is compromised. For instance, the mistrust/abuse schema ("People are only nice to me because they want something from me...People will use and manipulate me for their own gain people will hurt me") [26]. The result of maladaptive schemas is often this: You are left with those who feel threatened to stand up to you, or those that believe they have something to gain from indulging you. Your worst fear, being used, is ironically perpetuated by a coping mode that was originally designed to prevent that from happening to you [26]. In short, the facade that was to elevate the narcissist, may lead to them becoming the very fragile, worthless person they implicitly view themselves as. 


\section{Results}

In the manifesto, Kadacznski blames industrial society for a quality of life he deems "unfulfilling" and damaging to the natural world [27]. He repeats the well-worn mantra of sociologists of the nineteenth century who worried about alienation consequent to industrialization. According to him, we are living in conditions other than those we have evolved for [27]. He writes, "A few pre-industrialized cities were very large and crowded, yet their inhabitants do not seem to have suffered from psychological problems to the same extent as modern man" [27]. "Other indications of American social sickness," he explains, "are, for example, child abuse and the frequent inability to sleep or to eat normally...this chronic dissatisfaction and the sickly psychological condition of modern man are not normal and inevitable parts of human existence [28]. The ills of modern persons, he claims, cannot be solved through social engineering [27]. Technology is the problem, by which he notes "the broader sense of the word includes not only modern technology but also techniques and physical apparatus that existed at earlier stages of human society" [28]. As he puts it, "Thus, the problem of civilization can be equated with the problem of technology" [28]. According to him, we are like caged animals who try to achieve our goals: Lack of goals whose attainment requires effort leads to boredom, and that boredom long continued leads to depression. Failure to obtain goals leads to frustration and lowering of self-esteem. Frustration leads to anger, anger to aggression, often in the form of spouse or child abuse. It has been shown that long-continued frustration commonly leads to depression and depression can cause guilt, sleep disorders, eating disorders, and bad feelings about oneself.

Those who are tending towards depression seek pleasure as an antidote; hence insatiable hedonism and excessive sex, with perversion as a means of getting new kicks [27]. As Kaczynski sees things, human drives can be satisfied with

\section{Minimal effort, \\ II. With serious effort, \\ III. Not at all.}

For him, modern society gives rise to artificial desires that are satisfied with great effort, and with the rest of our desires being easily obtained (e.g., food) or not at all (e.g., connectedness, identity). The situation, thus, is one where the effort we need to exert to meet our basic needs is no longer needed, or futile. What we do strive for is unnecessary. And what we really need is rarely obtained. Yet the manifesto is not what one would suspect. It is not a rant against technological society, as much as a critique of the left. He claims that leftists are motivated by feelings of inferiority and are over-socialized, in the sense they accept the norms of society than most [27].

Their low self-esteem, powerlessness, depressive tendencies, defeatism, guilt and self-hatred motivate the left, according to him. As he describes the leftist: He is fond of using common catch phrases of the left like 'racism,' 'sexism,' 'homophobia,' 'capitalism,' 'imperialism,' 'neo-colonialism,' 'genocide,' 'social change,' 'social justice,' 'social responsibility.' Maybe the best diagnostic trait of the leftist is his tendency to sympathize with the following movements: feminism, gay rights, ethnic rights, disability rights, animal rights, political correctness [27]. One result: "Today, weak and sickly babies survive to pass on their defective genes" [27]. As he explains, the system requires-racial, sexual, etc-harmony, so that everyone will work together [28]. Strive only causes friction. He goes on: Though they like to fancy themselves independent thinkers, the intellectuals are (allowing for exceptions) the most over-socialized, the most conformist, the tamest, and the most domesticated, the most pampered, dependant, and spineless group in America today. As a result, their impulse to rebel is particularly strong.

But because they are incapable of independent thought, real rebellion is impossible for them. Consequently, they are suckers for the system's trick, which allows them to irritate people and enjoy the illusion of rebellion without ever having the challenge the system's basic values [27]. Against the backdrop of "what is wrong" with the world, one infers that the ideal society for Kaczynski is one free of technology. Indeed, the life he sought out was one that was apart from the conveniences of modern society, like running water and electricity. Yet in an essay, collected together in Technological Slavery: The Collected Writings of Theodore J. Kaczynski, a.k.a. "The Unabomber," titled "The Truth of Primitive Life: A Critique of Anarcho-Primitivism," he offers cautionary notes: I further agree that a revolution against modernity and civilization in general is necessary. But you can't build an effective revolutionary movement out of soft-headed dreamers, laziest, and charlatans. You must have tough-minded, realistic, practical people, and people of that kind don't need an anarcho-primitivists mushy utopian myth [28]. Since a young age, however, he sought "escape from civilization" [28], influenced by works like Robinson Crusoe. Even though much criticism he has received relate to the unoriginality of his thought, he counters that is not the point [28]. His goal was not to say something new, but something he thought true. His truth goes like this. He was unable to find fulfilment in life as a professor of mathematics at the University of Berkeley. He explains: If I had worked on applied mathematics I would have contributed to the development of the technological society that I hated, so I worked only on pure mathematics. But pure mathematics was only a game. I did not understand then, and still do not understand, why mathematicians are content to fritter away their whole lives in a mere game. I myself was completely dissatisfied with such a life [28].

\section{In fact, he offers a first-hand account of his thinking that led him to becoming a terrorist}

I felt so miserable [at age 24] I did not care if I lived or die. But when I reached that point, a sudden change took place: I realized that if I didn't care if I lived or died, then I didn't need to fear the consequences of anything I might do. Therefore, I could do anything I wanted. I was free! [28]. The epigram for [29] Harvard and the 
Unabomber: The Education of an American Terrorist is from Hanna Arendt: "An idealist lives for ideas and will sacrifice everything, and everybody, for it." The line of reasoning is that being committed to ideas, by nature abstract, could compromise our concern for individuals. Using Arendt's epigram in the context of his book suggests that for Chase Kaczynski was committed to some ideals, and not just driven by derangement, though we can ask, how logical are his views? A court appointed forensic psychologist, Sally C. Johnson, examined him in 1988. She concluded that Kaczynski merged two belief systems:

\section{Society is bad, hence we must rebel}

2. Intense anger at his family for perceived injustices.

The theme running through both points is that someone or thing is responsible for his unhappiness.

The purpose of Chase's book is to trace how Kaczynski's education groomed him for his life as a terrorist. He became the quintessential alienated intellectual. According to Chase, noting a madman has lost everything but his reason, Kaczynski had an "excess of reason". He was condescending, arrogant, and certain of his thinking. His philosophical views were shaped by positivism and emotivism. By positivism, he believed, ironically (because against technology!), that science was the best way to find answers to questions; and by emotivism, he held that morality is a ruse, or at least, nothing more than expression of emotions. Based on the research of [30], Kaczynski displayed resentment when he learned his neighbour had married. It is speculated that Kaczynski killed several of his neighbour's dogs and sabotaged a millfinding the noise disturbing-and set booby-traps to harm off-road motorcyclists. He may even have attempted to shoot at a helicopter.

One way to interpret his behaviour is thus. Kaczynski was genuinely concerned about the encroachment of human beings into natural areas and sought a Thoreau-like solace in nature. Yet his own writings betray something else entirely. I believe in nothing. Whereas I don't even believe in the cult of nature-worshippers or wilderness worshippers. (I am perfectly ready to litter in parts of the woods that are of no use to me-I often throw cans in loggedover areas or in places much frequented by people; I don't find wilderness particularly healthy; I don't hesitate to poach [30]. As Kaczynski put it, "I'll just chuck all of this silly morality business and hate anybody I please. Since then I have never had any respect for morality, ethics, or anything of the sort" [30]. Again, "I hate people". Further, and more specifically: "I felt I wouldn't care if I died. And so, I said to myself, 'why not kill that psychiatrist and anyone else I hate" [30].

Insight into his upbringing have been provided by his brother, David, in Every Last Tie: The Story of the Unabomber and his Family. In about the seventh or eighth grade, David asked his mother what was wrong with Ted, why he had no friends. His mother reassured him that Ted was just different. She traced Ted's difference to early separation due to a hospital stay, which makes him fear abandonment. Further, when the family had to move, Ted felt threatened and firmly proclaimed of the movers, "make them go away" [31]. Also, one incidence that is recalled by David, is Ted's overtures towards a woman; when rejected he posted obscene limericks about her where she worked.

The question, I believe, then, is not solely about the merits of Kaczynski's writings about technology-but rather, why he has such intense rage. Why does he, "hate people"? As for the content of his writings, suffice it to say, there are some interesting remarks about leftists, but it is not clear he offers any realistic solution. It is easier to know what is wrong (poverty, war, etc.) than make it right, which is not to say we should not try, but at the same time be cautious to someone who has seeming all the answers (recall Arendt's words!). So, I thus turn away from the content of Kaczynski's writings, and to what could be motivating him. Clearly, he is not driven by moral concerns.

\section{Conclusion}

According to the DSM-5, there are two way of approaching personality disorders. We can think of them categorically, as having qualitatively different syndromes; or take, as I do, a dimensional approach, whereby maladaptive varieties of personality traits overlap and merge with each other (e.g., borderline PD, anti-social/ psychopathic, schizoid, OCD) $[3,18,32]$. It is possible that one could be diagnosed with more than one personality disorder. Indeed, Park Dietz saw Kaczynski not as psychotic, but more as a schizoid or schizotypal personality disorder. Generally, a diagnosis for a personality disorder requires understanding one's inner experience (e.g., cognition, how the world is perceived; affect, range, intensity, appropriateness; interpersonal functioning; and impulse control). Also considered is one's long-term pattern of behaviour, which, to make a diagnosis, cannot be better explained by another illness, and is not physiological (e.g., drug induced).

In fact, we are cautioned not to diagnosis a personality disorder, like paranoid personality disorder, if there are cultural differences or an overlap with schizophrenia, bipolar of depression with psychotic features. The sort of overlap that interests us, however, is that with other personality disorders. In what follows, I indicate in parenthetical brackets where there is overlap with personality disorders other than NPD. Generally, Kaczynski has the markers of a personality disorder. He perceives the world as an unloving place, one that abandons people, be this his family or technological society-both of which he rails against. His counterattack against the perceived cause of his suffering takes the form of mail bombs to leaders of technological innovation; and hurtful letters to his family, complaining of perceived mistreatment by them. His impulse control is in question because he cannot control his ragedecidedly dedicated to revenge, having in his own account, no other purpose to live. He fits, more specifically, the mode of narcissism in important ways. He is very sensitive to slights, as we recall his extreme reaction to the rejection of his overtures towards a girl where he worked; he reacts with rage. He uses others, and when they get in his way, he can become dangerous. 
He has a sense of superiority, partly reinforced by his academic achievements, but still requiring an audience; for example, he wanted his manifesto published on pain of killing others, which also shows lack of empathy [33-36]. Though ethnic superiority is not a notable theme in his writings, his critique of the left, does hint at some sense of at least not being part of vulnerable populations. It is plausible that part of his intense desire not to be labeled "mentally ill" is due to maintaining his sense of superiority. Obviously, he engaged in risky behaviour, which eventually led to his capture. He had few friends, if any, and even relationships with family were virtually non-existent. In fact, he blames not only technological society, but his family for various perceived misdeeds (as is common with a paranoid personality disorder, he is suspicious of others, bears grudges, is unforgiving, and seeks to counterattack, yet departing from this type, he does not quite reach the threshold that this is the main theme). He chose a solitary life, leaving his job and moving to a cabin in Montana with no electricity or running water (a pervasive pattern of detachment from social relations is typifies a schizoid personality disorder, though unlike this type, Ted did want intimacy that he failed to achieve).

Recall, even his brother David inquired about Ted's solitary nature, when quite young. Ted's fear of abandonment was on full display when he reacted strongly to a family move. Though his mother traced Ted's "difference" to fear of abandonment triggered by early separation due to a hospital visit, it is reasonable to conjecture that he was genetically disposed towards narcissism, even once we grant his background, including his education, may have been contributing factors. In fact, he is distressed by his situation by the very fact that he seeks an intimacy he cannot claim. Not being able to develop a trusting relationship, there was few mitigating factors that allowed him to develop for adaptive relationship schemas. In fact, he leaves behind him a trail of broken relationships, with his father, mother, and brother, among others.

And, in the end, he ended up alone, without much freedom, and under control in an industrial-like prison, a super-max in Florence, Colorado, that is, the very way he perceived his external world to be-uncaring. Technological society abandoned him, and he wanted payback. My interest in Kaczynski's case stems in part from some overlap in our background. He was an academic, and I am one. He was apparently concerned about the effects of technology on human well-being, as I have been, and continue to be. Specifically, I am concerned about how a host of so-called experts (e.g., social workers, psychologists, medical professional, and applied science more generally) pave the way to a world that is potentially less human, where we are less connected to each other and the land.

In fact, Kaczynski chose pure mathematics as a vocation, because he did not want to participate in the development of technology he detested. Having taught courses in education, psychology, and social work, I have also worried if I am not participating in a system. I have qualms with. Admittedly, there are differences. I believe that at least sometimes the pros (the discovery of knowledge) outweigh the cons (the questionable application of knowledge). He purportedly was concerned about the environment, and I have been active with such concerns, though mine were focused on animal rights, something he was critical about as part of "leftism." My concern for animals is sincere, and we cannot say the same for Kaczynski. And I selfidentify in Canada as a visible minority, of Indian-Punjabi ancestry, another trait that, in his mind, disposes me towards leftism, or at least the attention of those of that ilk.

Though the social ills Kaczynski identifies are well-worn, his solutions range from obscure (criticizing "the system") to dangerous, illegal, unethical, and bizarre. After all, even if we were to grant some of what he claims, it is not at all clear how sending bombs to various people changes anything. What is his purpose other than to express rage and to harm others? That is, it is very important to him to be taken seriously, and that his ideas are not undermined as stemming from a mental illness. But his pattern of thinking and behaving, grandiose ideas, blaming the world, extreme isolation, and failure in interpersonal relationships are tell-tale signs of a mental illness. It is clear to me that he has not been able to reach his potential as a human being; his own words emphasize distress stemming from the lack of intimacy.

In fact, much of his political writings I have sighted are replete with psychological language that could be read as a personal letter: he has found modern life to be unsatisfactory, and more specifically, his life to be meaningless. The cause of his distress he pins on technological society and his family. Nowhere does it occur to him that he, even in part, that he may be the cause of his misery, which is not surprising giving my account. Ted suffers from interpersonal deficits that I have detailed as a personality disorder of the narcissistic type. The term narcissism is an allusion to a Greek myth retold in Homeric hymns and Ovid's Metamorphoses of a youth admired for his beauty but one who rejected those who admired him; punished by Nemesis, he was condemned to unrequited love. He was paralyzed by his own image in a pool of water till his death $[37,38]$. As an allegory, the myth sounds a lot like Ted.

As noted at the outset, his abnormal psychology is blended with his social concerns resulting in acts of domestic terrorism. It is for others to see how many other terrorists are motivated by narcissistic personality disorder, a quality that may be encouraged in leaders of such groups by followers, whom they seek and need.

From the standpoint of educational intuitions, the following practitioner points are worth noting:

a. Making it part of the mission of institutions of learning to address issues of interpersonal disturbances, often a red flag of a variety of mental disorders.

b. Fostering a sense of belonging among students, which may be linked to nationalism or religion, when appropriate.

c. Expanding the mandate of higher education to be more concerned with the socio-emotional and psychological well-being of students.

Integrating into all courses of study opportunities for kinesthetic movement, collaboration, social interactions. 


\section{References}

1. American Psychiatric Association (2000) Diagnostic statistical manual of mental disorders ( $5^{\text {th }}$ edn), Washington, USA.

2. Reynolds EK, Lejuez CW (2011) Narcissism in the DSM. In: Campbell WK, Miller JD (Eds.), The handbook of narcissism and narcissistic personality disorder: Theoretical approaches, empirical findings, and treatments, Wiley, New Jersey, USA, pp. 14-21.

3. Watson C, Bagby RM (2011) Assessment of narcissistic personality disorder. In: Campbell WK, Miller JD (Eds.), The handbook of narcissism and narcissistic personality disorder: Theoretical approaches, empirical findings, and treatments, Wiley, New Jersey, USA, pp. 117-132.

4. Wallace HM (2011) Narcissistic self-enhancement. In: Campbell WK, Miller JD (Eds.), The handbook of narcissism and narcissistic personality disorder: Theoretical approaches, empirical findings, and treatments, Wiley, New Jersey, USA, pp. 309-318.

5. Reed-Knight B, Fischer S (2011) Treatment of narcissistic personality disorder symptoms in a dialectical behavior therapy framework: A discussion and case example. In: Campbell WK, Miller JD (Eds.), The handbook of narcissism and narcissistic personality disorder: Theoretical approaches, empirical findings, and treatments, Wiley, New Jersey, USA pp. 466-475.

6. Sandage SJ, Moe SP (2011) Narcissism and spirituality. In: Campbell WK Miller JD (Eds.), The handbook of narcissism and narcissistic personality disorder: Theoretical approaches, empirical findings, and treatments, Wiley, New Jersey, USA, pp. 410-420.

7. Holtzman NS, Strube MJ (2011) The intertwined evolution of narcissism and short-term mating: An emerging hypothesis. In: Campbell WK, Miller JD (Eds.), The handbook of narcissism and narcissistic personality disorder: Theoretical approaches, empirical findings, and treatments, Wiley, New Jersey, USA, pp. 210-220.

8. Miller JD, Maples J (2011) Trait personality models of narcissistic personality disorder grandiose narcissism, and vulnerable narcissism. In: Campbell WK, Miller JD (Eds.), The handbook of narcissism and narcissistic personality disorder: Theoretical approaches, empirical findings, and treatments, Wiley, New Jersey, USA, pp. 71-88.

9. Tracy JL, Cheng JT, Martens JP, Robins RW (2011) The emotional dynamics of narcissism: Inflated pride, deflated shame. In: Campbell WK, Miller JD (Eds.), The handbook of narcissism and narcissistic personality disorder: Theoretical approaches, empirical findings, and treatments, Wiley, New Jersey, USA, pp. 330-343.

10. Zeigler-Hill V, Jordon $\mathrm{CH}$ (2011) Behind the mask: Narcissism and implicit self-esteem. In: Campbell WK, Miller JD (Eds.), The handbook of narcissism and narcissistic personality disorder: Theoretical approaches, empirical findings, and treatments, Wiley, New Jersey, USA, pp. 101 115.

11. Hogan R, Fico J (2011) Leadership. In: Campbell WK, Miller JD (Eds.), The handbook of narcissism and narcissistic personality disorder: The oretical approaches, empirical findings, and treatments, Wiley, New Jersey, USA, pp. 393-402.

12. Sedikides C, Ciske S, Hart CM (2011) Narcissism and brand name consumerism. In: Campbell WK, Miller JD (Eds.), The handbook of narcissism and narcissistic personality disorder: Theoretical approaches, empirical findings, and treatments, Wiley, New Jersey, USA, pp. 382-392.

13. Myer B, Pilkonis PA (2011) Attachment theory and narcissistic personality disorder. In: Campbell WK, Miller JD (Eds.), The handbook of narcissism and narcissistic personality disorder: Theoretical approaches, empirical findings, and treatments, Wiley, New Jersey, USA, pp. 434-444.
14. Simonsen S, Simonsen E (2011) Comorbidity between narcissistic personality disorder and Axis I diagnoses. In: Campbell WK, Miller JD (Eds.), The handbook of narcissism and narcissistic personality disorder: Theoretical approaches, empirical findings, and treatments, Wiley, New Jersey, USA, pp. 237-247.

15. Bosson JK, Weaver JR (2011) I love me some me: Examining links between narcissism and self-esteem. In: Campbell WK, Miller JD (Eds.), The handbook of narcissism and narcissistic personality disorder: Theoretical approaches, empirical findings, and treatments, Wiley, New Jersey, USA, pp. 261-271.

16. Foster JD, Brennan JC (2011) Narcissism, the agency model, and approach-avoidance motivation. In: Campbell WK, Miller JD (Eds.), The handbook of narcissism and narcissistic personality disorder: Theoretical approaches, empirical findings, and treatments, Wiley, New Jersey, USA, pp. 89-100.

17. Morf CC, Torchetti L, Schürch E (2011) Narcissism from the perspective of the dynamic self-regulatory processing model. In: Campbell WK, Miller JD (Eds.), The handbook of narcissism and narcissistic personality disorder: Theoretical approaches, empirical findings, and treatments, Wiley, New Jersey, USA, pp. 56-70.

18. Oltmanns TF, Lawton EM (2011) Self-other discrepancies. In: Campbell WK, Miller JD (Eds.), The handbook of narcissism and narcissistic personality disorder: Theoretical approaches, empirical findings, and treatments, Wiley, New Jersey, USA, pp. 300-308.

19. Owings WA, Kaplan LS (2013) Leadership and organizational behaviour in education: Theory into practice. Pearson, New York, USA.

20. Hill PL, Roberts BW (2011) Examining the developmental me: A review of narcissism as a life span construct. In: Campbell WK, Miller JD (Eds.), The handbook of narcissism and narcissistic personality disorder: Theoretical approaches, empirical findings, and treatments, Wiley, New Jersey, USA, pp. 191-201.

21. Lynam DR (2011) Psychopathy and narcissism. In: Campbell WK, Miller JD (Eds.), The handbook of narcissism and narcissistic personality disorder: Theoretical approaches, empirical findings, and treatments, Wiley, New Jersey, USA, pp. 272-282.

22. Buffardi LE (2011) Narcissism and the world wide web. In: Campbell WK, Miller JD (Eds.), The handbook of narcissism and narcissistic personality disorder: Theoretical approaches, empirical findings, and treatments, Wiley, New Jersey, USA, pp. 371-381.

23. Widiger TA (2011) The comorbidity of narcissistic personality disorder with other DSM-IV personality disorders. In: Campbell WK, Miller JD (Eds.), The handbook of narcissism and narcissistic personality disorder: Theoretical approaches, empirical findings, and treatments, Wiley, New Jersey, USA, pp. 248-260.

24. Clifton A (2011) Narcissism and social networks. In: Campbell WK, Miller JD (Eds.), The handbook of narcissism and narcissistic personality disorder: Theoretical approaches, empirical findings, and treatments, Wiley, New Jersey, USA, pp. 360-370.

25. Brunell AB, Campbell WK (2011) Narcissism and romantic relationships: Understanding the paradox. In: Campbell WK, Miller JD (Eds.), The handbook of narcissism and narcissistic personality disorder: Theoretical approaches, empirical findings, and treatments, Wiley, New Jersey, USA, pp. 344-350.

26. Behary WT, Dieckmann E (2011) Schema therapy for narcissism: The art of empathic confrontation, limit-setting, and leverage. In: Campbell WK, Miller JD (Eds.), The handbook of narcissism and narcissistic personality disorder: Theoretical approaches, empirical findings, and treatments, Wiley, New Jersey, USA, pp. 445-456. 
27. Kaczynski T (1995) The Unabomber manifesto: Industrial society and its future. Jolly Rogers, Berkeley, pp. 1-32.

28. Kaczynski T (2010) Technological slavery: The collection of writings of Theodore J Kaczynski, a.k.a. the Unabomber. Jolly Rogers, Berkeley.

29. Chase A (2003) Harvard and the Unabomber: The education of an American terrorist, Norton, New York, USA.

30. Waits C, Shors D (1999) Unabomber: The secret life of Ted Kaczynski. Helena, Toronto, Canada.

31. Kaczynski D (2016) Every last tie: The story of the Unabomber and his family. Duke University Press, Durham.

32. South SC, Eaton NR, Krueger RF (2011) Narcissism in official psychiatric classification systems: Toward DSM-5. In: Campbell WK, Miller JD (Eds.), The handbook of narcissism and narcissistic personality disorder: Theoretical approaches, empirical findings, and treatments, Wiley, New Jersey, USA, pp. 22-30.

33. Graysmith R (1996a) Zodiac. Berkeley, New York, USA.
34. Graysmith R (1996b) Zodiac unmasked: The identity of Americas most elusive serial killer. Berkeley, New York, USA.

35. Graysmith R (1997) Unabomber: A desire to kill. Regnery, Washington, USA.

36. Stewart GL, Mustafa S (2014) The most dangerous animal of all: Searching for my father and finding the Zodiac killer. Harper, New York, USA.

37. Levy KN, Ellison WD, Reynoso JS (2011) A historical review of narcissism and narcissistic personality. In: Campbell WK, Miller JD (Eds.), The handbook of narcissism and narcissistic personality disorder: Theoretical approaches, empirical findings and treatments, Wiley, New Jersey, USA, pp. 1-13.

38. Bushman BJ, Thomaes S (2011) When the narcissistic ego deflates, narcissistic aggression inflates. In: Campbell WK, Miller JD (Eds.), The handbook of narcissism and narcissistic personality disorder: Theoretical approaches, empirical findings, and treatments, Wiley, New Jersey, USA, pp. 319-329.
Creative Commons Attribution 4.0

International License

For possible submissions Click Here
Submit Article

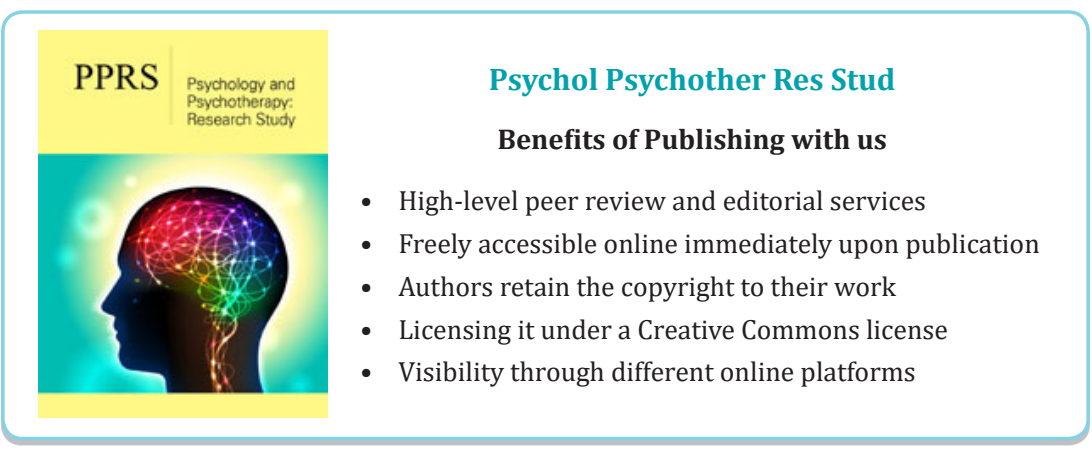

